Controversies exist around the prevention, surveillance and management of such thrombus.

We reviewed all cases of CVC related thrombus within the neonatal service over the last 3 years and to determine normal practice for managing such infants within the UK.

Methods Retrospective review of all cases of CVC related thrombus (as defined by any venous thrombus with an indwelling or recently removed catheter) within the last 3 years.

A national survey of the management of CVC related thrombus within tertiary neonatal units in the UK.

Results 7 infants (all pre term) were diagnosed with CVC related thrombus during the study period.

The national survey revealed no consensus for management. Conclusions CVC related thrombus has been associated with 1 death and significant morbidity within our service over the last 3 years.

Further work is urgently needed to determine the scale of the problem and best practice for management.

1 Haddad $\mathrm{H}$ et al. Routine Surveillance Ultrasound for the management of CVC in neonates. J Pediatr 2014 Jan;164(1):118-22

\section{P0-0497 RETROSPECTIVE AUDIT OF PREVALENCE, MANAGEMENT AND ASSOCIATED MORBIDITIES OF PDA IN PRETERM BABIES LESS THAN 30+0 WEEKS GESTATION IN A TERTIARY NEONATAL INTENSIVE CARE UNIT}

R Kumar, K Yajamanyam, A Singh. Neonatology, Birmingham Womens Hospital, Birmingham, UK

\subsection{6/archdischild-2014-307384.1143}

Background Patent ductus arteriosus (PDA) causes significant morbidity and a dilemma of whether, when or how to manage in extremely preterm babies.

Aim Retrospective observational cohort study of the prevelance, managment and associated morbidities of PDA in preterm babies less than $30^{+0}$ weeks gestation.

Methods The Badger database was interrogated for babies born less than $30^{+0}$ weeks gestation between $01 / 04 / 09$ and 31/03/12. The prevalence, management and associated morbidities of babies with PDA were compared to those without a PDA.

Results 300 babies less than $30^{+0}$ gestation were admitted to the tertiary neonatal unit. PDA was confirmed on echocardiography in 192 (64\%) babies. 85 babies had medical and/or surgical treatment.

Conclusion Our retrospective cohort study demonstrates that despite the reduction in mortality and severe IVH in babies treated with indomethacin or had surgical ligation, their respiratory morbidities remain significant. Early targeted management of PDA may reduce these morbidities.

\section{PO-0498 WITHDRAWN}

\section{PO-0499 WITHDRAWN}

\section{PO-0500 ANTENATAL DIAGNOSIS OF CARDIOVASCULAR MALFORMATIONS IN INFANTS OF DIABETIC MOTHERS: A DGH EXPERIENCE}

J Mahadevan, M Abu-Harb. Neonates, Sunderland Royal Hospital, Sunderland, UK

\subsection{6/archdischild-2014-307384.1144}

Background Pre-existing maternal diabetes is associated with a five-fold increase in the prevalence of congenital cardiovascular malformation (CVM). NICE guidelines recommend that pregnant women with diabetes should be offered antenatal examination of the four-chamber view of the fetal heart and outflow tracts at 18-20 weeks to detect congenital malformations.

Aim The primary objectives of the audit were to find out the prevalence of CVM in infants of diabetic mothers and the success rate of fetal-echocardiography in diagnosing CVM antenatally. Our secondary objectives were to find out the number of diabetic mothers booked for delivery at the Sunderland Royal Hospital and the percentage of diabetic pregnancies referred for antenatal cardiac screening.

Methods This was a retrospective audit. Data was collected from all diabetic mothers booked for antenatal care between April 2004 and December 2008 and the corresponding cohort of infants with cardiovascular malformations born between May 2004 and May 2010.

Results $89 \%$ of the 102 diabetic mothers had undergone antenatal cardiac screening. 180 infants were born with CVM during the study period $(1.09 \%$ of total births). Of these, five infants were born to diabetic mothers (4.9\%). Fetal echocardiogram gave the correct diagnosis in $96.7 \%$ of the cases with a specificity of $100 \%$ and a sensitivity of $25 \%$.

Conclusions $89 \%$ of the diabetic mothers had undergone antenatal cardiac screening. Maternal diabetes is associated with 4.9\% risk of CVM. VSD is the most common CVM in maternal diabetes. Fetal echocardiogram gave the correct diagnosis in $96.7 \%$ of the cases.

\begin{tabular}{|c|c|c|c|}
\hline & No PDA $(n=108)$ & PDA not treated $(n=107)$ & PDA treated $(n=85)$ \\
\hline M:F & $57: 51$ & $54: 53$ & $39: 46$ \\
\hline Median Gestation (range) & $28(27-28)$ & $26(24-27)$ & $25(24-26)$ \\
\hline Median Birth Weight (range) & 1087 (839-1222) & 785 (656-945) & 755 9650-880) \\
\hline Median Ventilation days (range) & $2(1-6)$ & $7(3-15)$ & $20(7-29)$ \\
\hline Median CPAP days (range) & $2.5(0-17)$ & $14(3-15)$ & $31(14-42)$ \\
\hline Supplemental 02 days (range) & $8(2-30)$ & $31(10-73)$ & $60(27-100)$ \\
\hline CLD (36 weeks CGA) & $14(13 \%)$ & $27(25 \%)$ & $35(41 \%)$ \\
\hline Home Oxygen & $5(4 \%)$ & $13(12 \%)$ & $14(16 \%)$ \\
\hline NEC & 7 96\%) & $14(13 \%)$ & $14(16 \%)$ \\
\hline IVH > Grade 3 & $11(10 \%)$ & $23(21 \%)$ & $9(10.5 \%)$ \\
\hline Death & $31(29 \%)$ & $36(34 \%)$ & $13(15 \%)$ \\
\hline
\end{tabular}

